\title{
O mercado de energia elétrica: comportamento recente
}

\section{PAULO DE VILHENA BRANDÃO}

Chefe do Departamento de Mercado da Diretoria de Planejamento e Engenharia da ELETROBRÁS e coordenador do Comité Técnico para Estudos de Mercado do Grupo Coordenador do Planejamento do Sistema Elétrico GCPS.

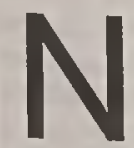
o periodo 1970/85, o consumo total de energia elétrica no Brasil (inclusive a parcela referente aos autoprodutores) apresentou uma taxa geométrica média de crescimento de $10,6 \%$.

Neste mesmo período, o PIB (Produto Interno Brutol cresceu a $6,3 \%$. No período 1970/84 o Consumo Final Energético, onde são considerados todas as formas de energia, cresceu à taxa de $6,0 \%$ a.a., conforme dados básicos apresentados no Quadro 1.

O reflexo desse crescimento se dá na crescente participação e penetração da energia elétrica no Consumo Final Energético do país, pois sua participação cresceu de $19 \%$, em 1970 , para $35 \%$, em 1984 , conforme mostra o Quadro 2

Um outro fator que se pode destacar é o de que as variaçōes conjunturais do PIB afetam com maior rapidez o consumo de energia total que o de energia elétrica, ou seja, é maior a rapidez de resposta do consumo de outras fontes de energia às variaçōes do PIB. Is to pode ser explicado por vários motivos, o primeiro dos quais é de que a energia elétrica participa, sem exceção, de todos os setores da atividade econômica, intermediários e finais, quer sujeitos, imediatamente ou não, à influência direta das va. riações do PIB, conforme pode ser verificado, principalmente, no periodo 1981/83, quando, mesmo com taxas negativas de crescimento do PIB (de 1,9 e 3,3 nos anos de 1981 e 19831, o mercado de energia elétrica apresentou taxas de crescimento positivas (respectivamente de 2,6 e $7,7 \%$ ) e o Consumo Final Energético, taxa negativa (de 3,1 ) e positiva (de 3,2) nos mesmos anos.

Desse modo, as forças em jogo que determinam e condicionam o consumo de energia elétrica são mais diversas e de

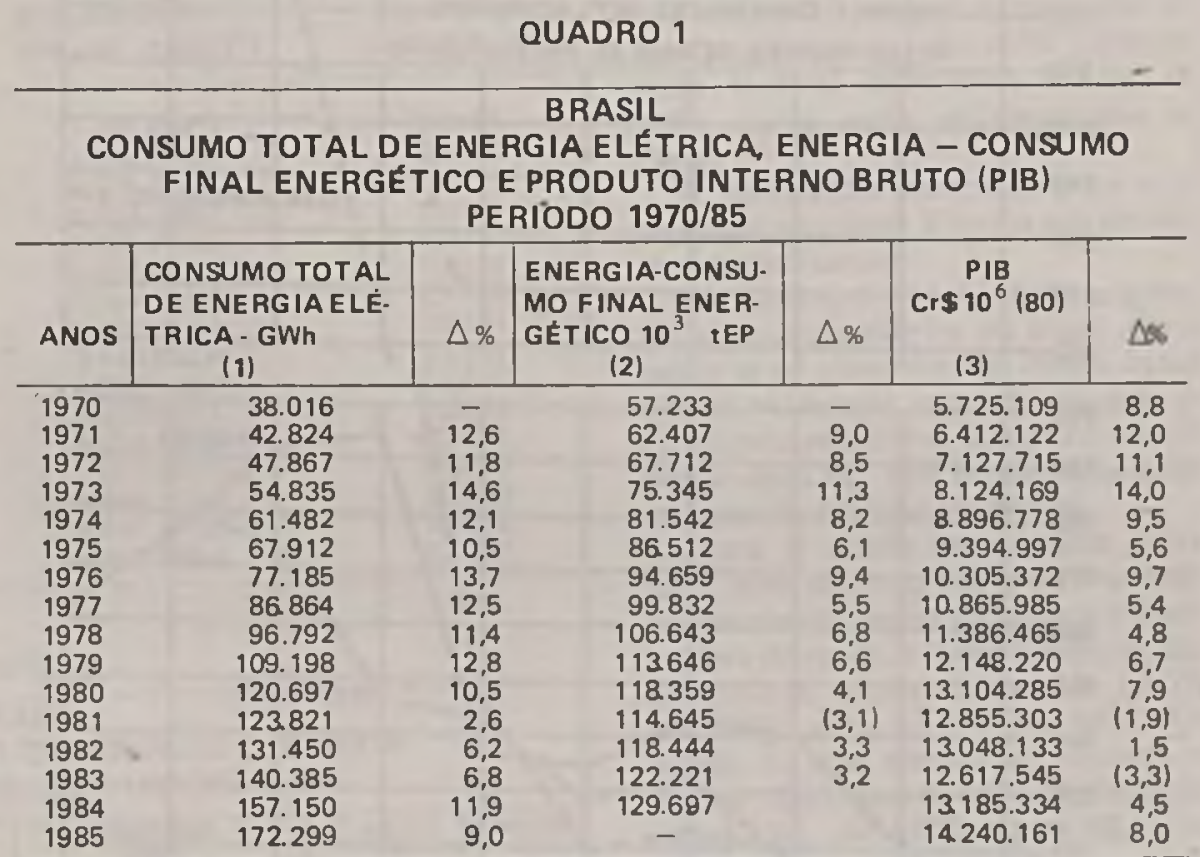

Fontes: (1) ELETROBRÁS/DEME (Inclui Autoprodutores)

(2) Balanço Energético Nacional 1984 - MME - Tabela 5.2.1, pág. 42

(3) Brasil, Macrorregizes Fisiograficase Estados das Reqiöes Sudeste e Sul - Estima tivas e Projeç̧ões de Renda Interna e Setorial, 1970/2010 - GCPS/CTEM/ GTME - Maio/84 - Quadro VI - pág. 1-7.

QUADRO 2

CONSUMO FINAL ENERGÉTICO E CONSUMO TOTALDE ENERGIA ELETRICA*

\begin{tabular}{|c|c|c|c|}
\hline \multirow[b]{2}{*}{ ANOS } & \multicolumn{2}{|c|}{$10^{3}$ tEP } & \multirow[b]{2}{*}{$\begin{array}{l}\text { PART. } \% \\
(1) /(2)\end{array}$} \\
\hline & $\begin{array}{l}\text { CONSUMO TOTAL DE } \\
\text { ENERGIA ELETRICA (1) }\end{array}$ & $\begin{array}{l}\text { CONSUMO FINAL } \\
\text { ENERGETICO (2) }\end{array}$ & \\
\hline 1970 & 11.025 & 57.233 & 19,3 \\
\hline 1971 & 12419 & 62.407 & 19,9 \\
\hline 1972 & 13.881 & 67.712 & 20,5 \\
\hline 1973 & 15.902 & 75.345 & 21,1 \\
\hline 1974 & 17.830 & 81.542 & 21,9 \\
\hline 1975 & 19.694 & 86.512 & 22.8 \\
\hline 1976 & 22.384 & 94.659 & 23,6 \\
\hline 1977 & 25. 191 & 99.832 & 25,2 \\
\hline 1978 & 28.070 & 106.643 & 26,3 \\
\hline 1979 & 31.667 & 113.646 & 27,9 \\
\hline 1980 & 35.002 & 118.359 & 29,6 \\
\hline 1981 & 35.908 & 114.645 & 31,3 \\
\hline 1982 & 38121 & 118444 & 32.2 \\
\hline 1983 & 40.992 & 122.221 & 33.5 \\
\hline 1984 & 45.888 & 129.697 & 35,4 \\
\hline
\end{tabular}

- Fonte dos dados basicos - Quadro 1

(1) Coef. de conversão 0,292 tEP/MWh 
FIGURA 1
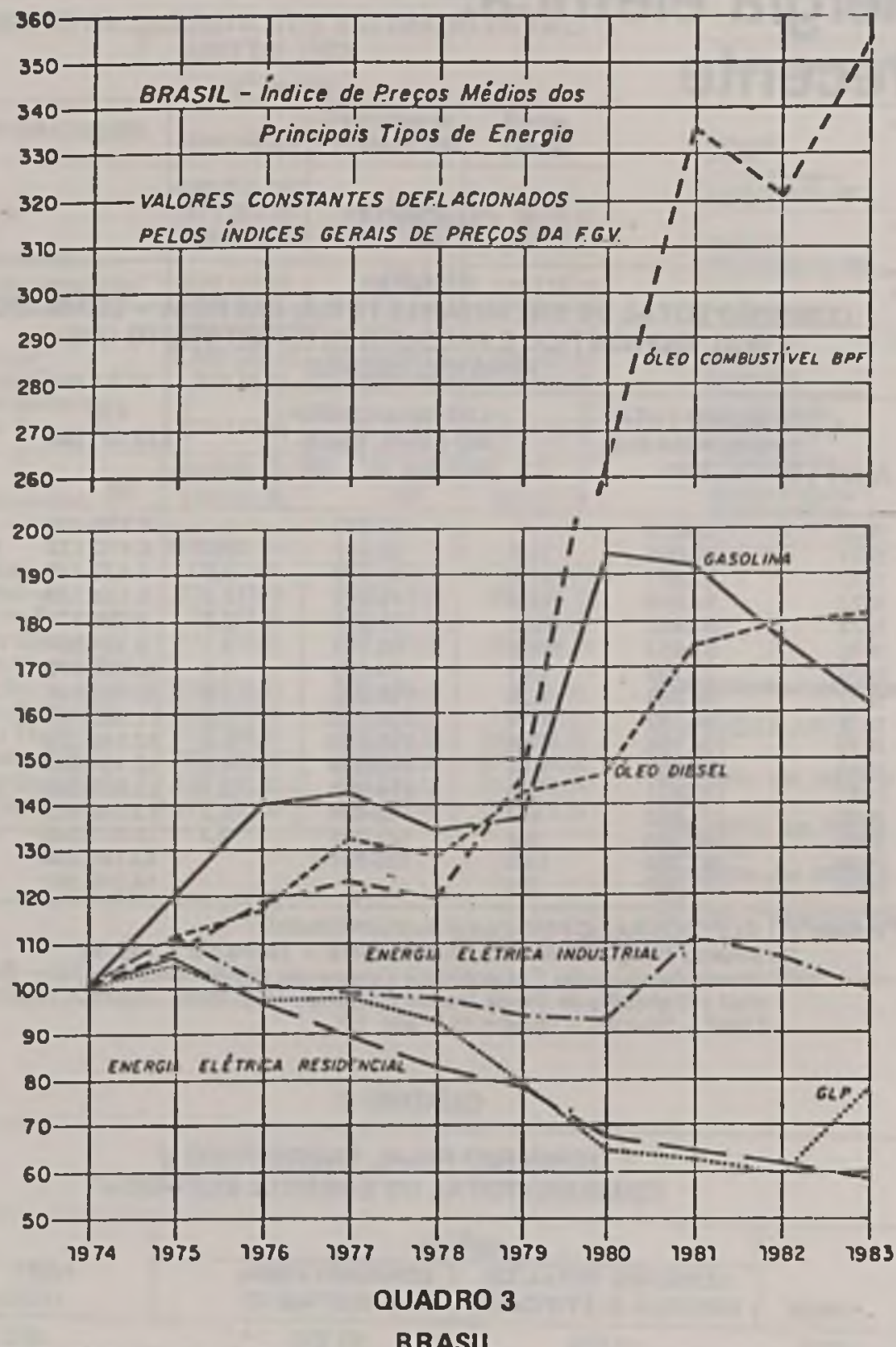

CONSUMO TOTAL DE ENERGIA ELÉTRICA*

\begin{tabular}{l|c|c|c|c}
\hline ANOS & RESIDENCIAL & INDUSTRIAL & OUTRAS & TOTAL \\
1970 & 8.288 & 19.874 & 9.854 & 38.016 \\
1971 & 9.139 & 22.709 & 10.976 & 42.824 \\
1972 & 9.848 & 25.712 & 12.307 & 47.867 \\
1973 & 10.919 & 30.036 & 13.880 & 54.835 \\
1974 & 11.998 & 33.980 & 15.504 & 61.482 \\
1975 & 13.208 & 37.509 & 17.195 & 67.912 \\
1976 & 14.842 & 43.453 & 18.890 & 77.185 \\
1977 & 17.122 & 49.090 & 20.652 & 86.864 \\
1978 & 18.878 & 55.360 & 22.554 & 96.792 \\
1979 & 21.098 & 63.164 & 24.936 & 109.198 \\
1980 & 23.257 & 69.938 & 27.502 & 120.697 \\
1981 & 25.026 & 69.370 & 29.425 & 123.821 \\
1982 & 27.053 & 72.524 & 31.873 & 131.450 \\
1983 & 29.727 & 76.182 & 34.476 & 140.385 \\
1984 & 30.926 & 89.205 & 37.019 & 157.150 \\
1985 & 32.635 & 100.086 & 39.578 & 172.299 \\
\hline
\end{tabular}

Fonte: DEME/ELETROBRAS intensidades diferentes daquelas que animam a trajetória das demais fontes de energia. Quedas conjunturais do PIB são incapazes, por si so, de eliminar os efei. tos das forças em jogo de maior inércia, tais como o processo crescente de urbanização, o processo de aprimoramento tecnológico e o processo de substituição de derivados de petróleo por energia elétrica.

O mesmo pode ser dito quanto à tarifa, cujo resultado a curto prazo, de ordem conjuntural, tem pouco efeito sobre o consumo de energia elétrica. Os efeitos prolongados de tarifas decrescentes em termos reais, entretanto, geram efeitos multiplicadores, incentivando o uso crescente da energia elétrica, em substituição a outras fontes de energia. Quando, por motivo de excessos eventuais de oferta de energia elétrica combinados com restrições ao uso de derivados de petróleo, são oferecidas tarifas de incentivo à substituição, o consumo cresce de forma mais acelerada, como se observou a partir de 1982, com a instituição, entre outras, das tarifas de EGTD (Energia Garantida por Tempo Determinado) e de ESNG (Energia Sazonal Não Garantida).

Pode-se observar que o ritmo de crescimento do consumo total de energia elétrica que, no perfodo 1970/80 cresceu à taxa de $12 \%$, sofreu uma mudança brusca no ano de 1981, caindo para $2,6 \%$, com redução significativa da taxa de crescimento de todas as categorias de consumo, especialmente a industrial, que apresentou um decréscimo de $0,8 \%$.

As taxas de crescimento relativas aos anos de 1982/85 indicam, porém, uma tendência para a recuperação do ritmo observado anteriormente, apesar da persistência ou mesmo do agravamento da recessão econômica que o país atravessou.

Deve-se ressaltar nesse crescimento a contribuição do consumo proveniente da Eletrotermia (substituição de derivados de petróleo por energia elétrica), contribuição que representou em 1984 cerca de $5,4 \%$ do crescimento de $10 \%$ do consumo industrial.

Essa parcela demonstra a contribuição do Setor Elétrico ao esforço de substituição de derivados de petróleo, e sua importância pode ser medida quan. do, ao retirá-la do consumo total, a taxa de crescimento do ano de 1984 passa de $11,9 \%$ para $8,5 \%$.

Entre os fatores que contribuirarr para o crescimento do mercado de ener. gia elétrica no Brasil, deve-se destacar $c$ 
QUADRO 4

BRASIL

CONSUMO INDUSTRIAL CONSUMO ESPECIFICO DE ENERGIA ELÉTRICA

\begin{tabular}{|c|c|c|c|}
\hline ANOS & $\begin{array}{l}\text { CONSUMO } \\
\text { INDUSTRIAL } \\
\text { MWh (') }\end{array}$ & $\begin{array}{l}\text { PIB - SETOR } \\
\text { SECUNDARIO } \\
\text { Cr } \$ \times 10^{6}(1980)\left({ }^{2}\right)\end{array}$ & $\begin{array}{l}\text { CONSUMO } \\
\text { ESPECIFICO } \\
\text { kWh/PIB - SI }\end{array}$ \\
\hline $\begin{array}{l}1970 \\
1971 \\
1972 \\
1973 \\
1974 \\
1975 \\
1976 \\
1977 \\
1978 \\
1979 \\
1980 \\
1981 \\
1982 \\
1983 \\
1984 \\
1985\end{array}$ & $\begin{array}{r}19.873 .538 \\
22.708 .537 \\
25.712 .343 \\
30.035 .796 \\
33.979 .878 \\
37.508 .694 \\
43.453 .140 \\
49.089 .746 \\
53.359 .968 \\
63.164 .374 \\
69.937 .857 \\
69.369 .787 \\
72.524 .339 \\
76.182 .174 \\
89.205 .256 \\
100.086 .186\end{array}$ & $\begin{array}{l}1.488 .884,3 \\
1.948 .343,4 \\
2.236 .456,5 \\
2.604 .069,7 \\
2.836 .273,9 \\
2.994 .413,2 \\
3.364 .304,2 \\
3.491 .050,4 \\
3.440 .902,8 \\
3.982 .140,4 \\
4.294 .867,1 \\
4.054 .169,8 \\
4.077 .601,3 \\
3.808 .114 .6 \\
4.047 .751,8 \\
4.407 .491,4\end{array}$ & $\begin{array}{l}0,0133 \\
0,0116 \\
0,0115 \\
0,0115 \\
0,0120 \\
0,0125 \\
0,0129 \\
0,0141 \\
0,0161 \\
0,0159 \\
0,0163 \\
0,0171 \\
0,0178 \\
0,0200 \\
0,0220 \\
0,0227\end{array}$ \\
\hline
\end{tabular}

Fontes: (I) DEME/ELETROBRÁS

(2) GCPSNTEMIGTME

QUADRO 5

BRASIL

CONSUMO INDUSTRIAL DE ENERGIA ELÉTRICA SEGUNDO GËNEROS DE INDÚSTRIA

\begin{tabular}{|c|c|c|c|c|}
\hline \multicolumn{2}{|c|}{ GENEROS } & \multirow{2}{*}{ 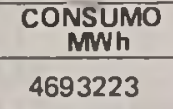 } & \multirow{2}{*}{$\frac{\Delta \underset{\%}{83 / 84}}{29,2}$} & \multirow{2}{*}{\begin{tabular}{|c}
$\begin{array}{c}\text { Estrutura } \\
\%\end{array}$ \\
6.09
\end{tabular}} \\
\hline $1-$ & Ind. Extrat. de Prod. Minerais & & & \\
\hline $11-$ & $\begin{array}{l}\text { Ind. de Transformação } \\
\text { Minerais não Metálicos } \\
\text { Metalurgia } \\
\text { Mecànica } \\
\text { Mat. Elétricos e de Comunicação } \\
\text { Material de Transporte } \\
\text { Madeira } \\
\text { Mobiliário } \\
\text { Papel e Papelão } \\
\text { Borracha } \\
\text { Couros, Peles e Similares } \\
\text { Química } \\
\text { Prod. Farm. e Veterinários } \\
\text { Perfumaria, Sabóes e Velas } \\
\text { Mat. Plástico e Resinas Sintéticas } \\
\text { Textil } \\
\text { Vestuário e Calçados } \\
\text { Produtos Alimentares } \\
\text { Bebidas } \\
\text { Fumo } \\
\text { Editorial e Gráfica } \\
\text { Outras Ind. de Transformação }\end{array}$ & $\begin{array}{r}71400575 \\
5023423 \\
25730638 \\
1704814 \\
1526715 \\
3368531 \\
900595 \\
312110 \\
3804492 \\
758442 \\
212528 \\
11082155 \\
560583 \\
106700 \\
1259687 \\
4612734 \\
596671 \\
7235747 \\
1050468 \\
170819 \\
377515 \\
1005209\end{array}$ & $\begin{array}{r}14.7 \\
-16.1 \\
15.2 \\
27.6 \\
6.5 \\
4.4 \\
-7.9 \\
-65.8 \\
13.7 \\
13.8 \\
9.5 \\
22.4 \\
31.9 \\
8.6 \\
8.0 \\
21.4 \\
12.9 \\
57.6 \\
35.9 \\
24.3 \\
9.6 \\
11.3\end{array}$ & $\begin{array}{r}92.69 \\
6.52 \\
33.40 \\
2.21 \\
1.98 \\
4.37 \\
1.17 \\
0.41 \\
4.94 \\
0.98 \\
0.28 \\
14.39 \\
0.73 \\
0.14 \\
1.64 \\
5.99 \\
0.77 \\
9.39 \\
1.36 \\
0.22 \\
0.49 \\
1.30\end{array}$ \\
\hline $111-$ & Construção Civil & 381253 & -17.9 & 0.49 \\
\hline IV - & Utilidade Pública & 83724 & 7.1 & 0.11 \\
\hline$v-$ & Peque nas Indústrias & 471829 & -12.5 & 0.61 \\
\hline VI - & Total & 77030604 & 15.1 & 100.00 \\
\hline
\end{tabular}

Notas: 1 - Os valores de 1984 säo preliminares

2 - Não inclui consumo de energis autoproduzida

3- TGM - Taxa Geométrica Média

4 - Esses dados se referem as principais concessionárias do Pais, cujo consumo industrial de energia elét. representam cerca de $95 \%$ do consumo industrial do Brasil.

Eletrobrás/DEME/DVAM da variação dos preços reais das tarifas de energia elétrica, que, embora nominalmente crescentes quando inflacionados pelo IGP (lindice Geral de Preços) da FGV, decresceram em 1983, em tarifas realmente correspondentes a cerca de $60 \%$ daquelas verificadas em 1974 para o consumo residencial e de $99 \%$ para o industrial, sendo que, neste caso específico, deve-se ter em conta a recuperação tarifária acontecida no ano de 1981, como pode ser visualizado na Figura 1.

A repercussão deste fato sobre o faturamento do Setor Elétrico nos últimos anos é significativa.

No Quadro 3, é apresentado o consumo de energia elétrica do Brasil, destacando-se os consumos das classes industrial e residencial, que são aquelas de maior peso específico. Juntas correspondem a cerca de $75 \%$ do consumo total, ao longo do periodo em análise.

Entre as classes de consumo, destaca-se, pelo seu peso relativo e importância económica como formadora e distribuidora de renda, a classe industrial. Sua participação relativa evoluiu de $52,3 \%$, em 1970, para 57,9\%, em 1980. Em função da crise econômica, iniciada no ano de 1981, esse percentual decresceu para $54,5 \%$, em 1983 , e para $58,1 \%$ no ano de 1985.

O Setor Industrial caminha segura. mente em direção de uma maior participação da capacidade instalada de equipamentos elétricos, comparadas à de de. rivados de petróleo e de outras fontes, por um processo de substituição autōnomo, derivado de aperfeicoamento tecnológico. Existe, sem dúvida, uma tendência para uma economia mais elétrica, vale dizer, mais eficiente.

Entre os anos de 1970 e 1975, o Censo Industrial revelou que a participação dos equipamentos de força motriz movidos à energia elétrica aumentou de $72,5 \%$ para $85,7 \%$.

No periodo em análise o consumo in. dustrial cresceu à taxa geométrica média de $11,4 \%$; e foi de $13,4 \%$ seu crescimento no período $1970 / 80$.

O bom desempenho das expor taçōes, o aumento da produção interna de petróleo e gás natural e a demanda do setor agrícola por máquinas, adubos e fertilizantes foram em 1984 as alavancas da recuperação da produção industrial.

A economia brasileira apresenta um retrato diversificado de tecnologias nos seus setores industriais. Ao lado de indústrias com tecnologias modernas - as do setor petroquímico e siderúrgico, por 
exemplo - há outras que se apóiam em tecnologias obsoletas, especialmente nos setores tradicionais.

No Quadro 4, mostra-se, no período 1970/85, a evolução do consumo específico de energia elétrica (que é a quantidade $\mathrm{kWh}$ por unidade de PIBI no Setor Industrial.

Os resultados apresentados na coluna referente ao Consumo Específico (kWh/ PIB-SI) demonstram maior penetração da energia elétrica, modificação na es. trutura de produçāo industrial e entrada de indústrias de consumo intensivo de energia elétrica, por unidade de produto.

A evidência destes fatores é explica. da nas taxas geométricas médias do periodo 1970/85, quando o PIB-SI cresceu a taxa de $7,5 \%$ e o consumo de energia elétrica industrial à taxa de $11,4 \%$, correspondendo a uma elasticidade-arco da ordem de 1,52.

Corroborando estas afirmativas é apresentado, no Quadro 5, o consumo industrial, segundo gêneros de indústria. Vale salientar que essas informaçōes são baseadas numa amostragem que abrange cerca de $96 \%$ das vendas de energia elétrica dos Concessionários, excluindo-se, neste caso, o consumo proveniente dos Autoprodutores.

Deve-se destacar que cerca de $70 \%$ do consumo industrial de energia elétrica concentram-se nos gêneros Metalurgia $(33,4 \%)$, Quimica $(14,4 \%)$, Produtos Alimentares $(9,4 \%)$, Minerais nāo Metálicos $(6,5 \%)$ e Têxtil $(6,0 \%)$.

No periodo em análise, o consumo residencial apresentou uma taxa geométrica média de crescimento de $9,6 \%$ e sua participaçāo tem sido da ordem de $20 \%$ em relação ao consumo total.

O crescente processo de urbanização e as evidências de que o estoque de aparelhos elétricos vem crescendo continuamente, estando ainda longe de um processo de saturação, são os responsáveis diretos pelos resultados alcançados.

No Quadro 6 é apresentado, juntamente com a evoluçāo do consumo residencial, a evolução de seus dois componentes básicos: o consumo por consumidor residencial e a taxa de atendi. mento residencial.

A taxa de atendimento residencial (rolaçāo percentual entre o número de consumidores residenciais e o número de domicílios) evoluiu de $32,0 \%$, em 1970 , para $59,0 \%$, em 1985 , o que indica que mais da metade do total de domicilios (urbanos e rurais) do Pais estão atendidos pelo Setor Elétrico, e es. te índice é, sem dúvida, o mais elevado entre os serviços básicos oferecidos à população.

Por outro lado, o consumo por consumidor residencial cresceu no mesmo período à taxa geométrica média de $1,6 \%$.

Esse indicador sofreu reduçōes nos anos de $1981 / 82 / 84$, conforme pode ser verificado no Quadro 6.

Deve salientar que nesse periodo houve uma acentuada queda de renda "per capita" do Brasil, com queda do salário real e da massa de salários, e o aumento médio da tarifa residencial se deu acima da variação do INPC.

Sob a denominação de OUTROS, com participaçäo de cerca de $25 \%$ do total, agregam-se os consumos das classes comercial, rural, poderes públicos, iluminação pública, água, esgoto e saneamento, tração elétrica, próprio e canteiro de obras.

No período 1970/85 estes consumos, englobadamente, apresentaram taxa média de crescimento de $9,7 \%$.

Particularizando-se esta taxa, referida ao mesmo período, teremos:

$\begin{array}{lc}\text { Comércio e Serviços } & 1970 / 85 \\ \text { Rural } & 9,5 \\ \text { Poderes Públicos } & 19,5 \\ \text { lluminação Pública } & 7,6 \\ \text { Ägua, Esgoto e Saneamento } & 11,8 \\ \text { Tração Elétrica } & 11,9 \\ \text { Próprio e Canteiro de Obras } & 3,8 \\ & 11,1\end{array}$

Em termos de consumo per capita de energia elétrica, os resultados apresentados no Quadro 9 mostram as evidências dessa redução das disparidades, pois este indice cresceu mais rapidamente em to das as regiōes, comparativamente ao crescimento da Região Sudeste e da média do pais.
Entre essas classes de consumo destaca-se, pelo seu peso relativo e imporviços. Sua taxa de crescimento anual foi de $9,5 \%$ no período em análise, indicando que, como prestador de serviços e área de contrato entre os Setores Primá. rios e Secundários e o Setor Final - que o Residencial - mostra um comcionantes que agem sobre aqueles seto res. De fato, a queda da renda disponivel do setor residencial tem efeito direto sobre os setores mencionados. Por outro ocorrendo no Setor Industrial, reorientada para as exportaçōes, inibe a participaçāo do Setor Secundário e Serviços, com repercussão sobre o consumo de energia elétrica. nos Quadros 7 e 8, houve um ganho relativo na participação das regiōes geográ. ficas do Brasil, com a perda de concentração do consumo na Região Sudeste, - que indica uma diminuição gradual das desigualdades regionais, pelo menos a nível do consumo de energia elétrica.
Espacialmente, conforme indicados
QUADRO 6

\section{BRASIL}

CONSUMO RESIDENCIAL DE ENERGIA ELÉTRICA E SEUS ÍNDICES BÁSICOS 1970/85

\begin{tabular}{|c|c|c|c|c|c|}
\hline ANOS & $\begin{array}{l}\text { CONSUMO } \\
\text { RESIDENCIAL } \\
\left.\text { GWh( }{ }^{1}\right)\end{array}$ & $\begin{array}{l}\text { N?.DE CONSUMIDORES } \\
\text { RESIDENCIAISI }^{1} \text { ) }\end{array}$ & $\begin{array}{c}\text { CCR } \\
\mathrm{kWh} / \text { anol } \\
2\end{array}$ & $\begin{array}{c}\text { NÜMERO DE } \\
\text { DOMICILIOS( }\end{array}$ & $\begin{array}{l}\text { TXR } \\
\left({ }^{4}\right)\end{array}$ \\
\hline $\begin{array}{l}1970 \\
1971 \\
1972 \\
1973 \\
1974 \\
1975 \\
1976 \\
1977 \\
1978 \\
1979 \\
1980 \\
1981 \\
1982 \\
1983 \\
1984 \\
1985\end{array}$ & $\begin{array}{r}8.288 \\
9.139 \\
9.848 \\
10.919 \\
11.998 \\
13.208 \\
14.842 \\
17.122 \\
10.878 \\
21.098 \\
23.257 \\
25.026 \\
27.053 \\
29.727 \\
30.926 \\
32.635\end{array}$ & $\begin{array}{r}6.669 .552 \\
7.159 .638 \\
7.674 .146 \\
8.315 .472 \\
8.884 .747 \\
9.474 .849 \\
10.365 .812 \\
11.326 .791 \\
12.298 .095 \\
13.392 .503 \\
14.557 .528 \\
15.724 .336 \\
17.101 .572 \\
18.358 .236 \\
19.466 .810 \\
20.596 .450\end{array}$ & $\begin{array}{l}1.243 \\
1.276 \\
1.283 \\
1.313 \\
1.351 \\
1.394 \\
1.432 \\
1.512 \\
1.535 \\
1.575 \\
1.597 \\
1.592 \\
1.582 \\
1.619 \\
1.589 \\
1.585\end{array}$ & $\begin{array}{l}20.864 .120 \\
21.670 .318 \\
22.624 .489 \\
23.344 .834 \\
24.216 .708 \\
25.098 .608 \\
26.001 .735 \\
26.782 .322 \\
27.871 .732 \\
28.808 .358 \\
29.733 .276 \\
30.737 .074 \\
31.757 .777 \\
32.792 .286 \\
33.842 .625 \\
34.821 .077\end{array}$ & $\begin{array}{l}32,0 \\
33,0 \\
34,0 \\
35,6 \\
36,7 \\
37,8 \\
39,9 \\
42,3 \\
44,1 \\
46,5 \\
48,9 \\
51,2 \\
53,8 \\
56,0 \\
57,5 \\
59,0\end{array}$ \\
\hline
\end{tabular}

Fonte: (I) DEME/ELETROBRAS

(2) Consumo por Consumidor Residencial

(3) População e Estoque Domiciliar, 1970/2010, por Macrorregiōes Fisiograficas e Unida des da Federaçäo - Jun/83 - GCPS/CTEM/GTME

(4) J axo de atendimento residencial 
QUADRO 7

\begin{tabular}{|c|c|c|c|c|c|c|}
\hline \multicolumn{7}{|c|}{$\begin{array}{c}\text { BRASIL E REGIÕES GEOGRAFICAS } \\
\text { CONSUMO TOTAL DE ENERGIA ELÉTRICA* } \\
\text { GWh } \\
1970 / 85\end{array}$} \\
\hline ANOS & NORTE & NORDESTE & SUDESTE & SUL & C. OESTE & BRASIL \\
\hline $\begin{array}{l}1970 \\
1971 \\
1972 \\
1973 \\
1974 \\
1975 \\
1976 \\
1977 \\
1978 \\
1979 \\
1980 \\
1981 \\
1982 \\
1983 \\
1984 \\
1985\end{array}$ & $\begin{array}{l}365 \\
435 \\
534 \\
658 \\
853 \\
988 \\
1.177 \\
1.323 \\
1.516 \\
1.779 \\
2.319 \\
2.507 \\
2.943 \\
3.213 \\
3.307 \\
3.792\end{array}$ & $\begin{array}{r}3.402 \\
3.885 \\
4.569 \\
5.540 \\
6.476 \\
7.433 \\
8.616 \\
10.221 \\
12.211 \\
14.173 \\
15.610 \\
16.734 \\
17.969 \\
20.059 \\
22.531 \\
25.507\end{array}$ & $\begin{array}{r}29.472 \\
33.158 \\
36.535 \\
41.320 \\
45.748 \\
49.825 \\
56.217 \\
62.415 \\
68.768 \\
76.935 \\
84.186 \\
84.817 \\
89.098 \\
93.634 \\
104.921 \\
113.732\end{array}$ & $\begin{array}{r}4.157 \\
4.609 \\
5.336 \\
6.177 \\
7.035 \\
8.035 \\
9.295 \\
10.646 \\
11.694 \\
13.272 \\
15.099 \\
15.976 \\
17.159 \\
18.581 \\
20.718 \\
23.023\end{array}$ & $\begin{array}{r}620 \\
738 \\
894 \\
1.140 \\
1.370 \\
1.631 \\
1.879 \\
2.258 \\
2.604 \\
3.038 \\
3.483 \\
3.787 \\
4.281 \\
4.898 \\
5.673 \\
6.245\end{array}$ & $\begin{array}{r}38.016 \\
42.824 \\
47.867 \\
54.835 \\
61.482 \\
67.912 \\
77.185 \\
86.864 \\
96.792 \\
109.198 \\
120.697 \\
123.821 \\
131.450 \\
140.385 \\
157.150 \\
172.299\end{array}$ \\
\hline
\end{tabular}

QUADRO 8

\begin{tabular}{|c|c|c|c|c|c|c|}
\hline \multicolumn{7}{|c|}{$\begin{array}{c}\text { BRASIL E } \\
\text { REGIOES GEOGRAFICAS } \\
\text { PARTICIPAÇĀO PERCENTUAL } \\
\%\end{array}$} \\
\hline ANOS & NORTE & NORDESTE & SUDESTE & SUL & C. OESTE & BRASIL \\
\hline $\begin{array}{l}1970 \\
1975 \\
1980 \\
1985\end{array}$ & $\begin{array}{l}1,0 \\
1,5 \\
1,9 \\
2,2\end{array}$ & $\begin{array}{r}8,9 \\
10,9 \\
12,9 \\
14,8\end{array}$ & $\begin{array}{l}88,9 \\
73,4 \\
69,7 \\
66,0\end{array}$ & $\begin{array}{l}10,9 \\
11,8 \\
12,5 \\
13,4\end{array}$ & $\begin{array}{l}1,6 \\
2,4 \\
2,9 \\
3,6\end{array}$ & $\begin{array}{l}100,0 \\
100.0 \\
100,0 \\
700,0\end{array}$ \\
\hline
\end{tabular}

QUADRO 9

\begin{tabular}{l|c|c|c|c|c|c}
\hline \multicolumn{7}{c}{ BRASIL E REGIŌES } \\
\multicolumn{7}{c}{$\begin{array}{c}\text { CONSUMO PER CAPITA DE ENERG IA ELÉTRICA } \\
\text { kWh/hab. }\end{array}$} \\
\hline ANOS & NORTE & NORDESTE & SUDESTE & SUL & C. OESTE & BRASIL \\
\hline 1970 & 100 & 120 & 733 & 251 & 120 & 405 \\
1975 & 207 & 234 & 1083 & 460 & 256 & 639 \\
1980 & 390 & 444 & 1624 & 788 & 455 & 1008 \\
1985 & 504 & 656 & 1590 & 1083 & 547 & 1272 \\
$1970 / 85$ & 11.3 & 12.0 & 5.3 & 10.2 & 10,6 & 7.9 \\
\hline
\end{tabular}


O Setor Elétrico é um dos que tem apresentado comportamento razoavelmente regular em meio à crise econômica recente.

As empresas que necessitam realizar pesados investimentos em geração, transmissäo e distribuição, particularmente as empresas geradoras e supridoras, com alto grau de expansão, decorrente do longo prazo de maturação de seus investimentos, foram estimuladas a captar recursos externos e têm sobrevivido à custa de endividamento crescente, uma vez que apenas as tarifas - contidas deste 1975 - não permitiram a auto-suficiência do Setor. Por mais adversa que tenha sido a política de viver à custa de empréstimo em moeda estrangeira, muitos deles com cláusulas vinculadas à compra de equipamentos no exterior e concorrências internacionais danosas para a indústria nacional, como para economia (efeito multiplicador), plena. mente capacitadas a atender as encomendas, ainda assim, por falta de opcão, parece que ela foi melhor do que a diminuição drástica dos investimentos que, diga-se de passagem, também nảo vêm crescendo em termos reais, cujos reflexos seriam altamente prejudiciais para a retomada do desenvolvimento econômico.

O problema de recursos, principalmente via tarifas reais, é agudo e a manutenção dessa política poderá ocasionar a deterioração dos serviços que o Setor Elétrico vem prestando à sociedade.

Para que o Setor Elétrico possa se adequar à necessária retomada do cres. cimento econômico, será preciso man. ter as tarifas em niveis reais e selecionar melhor os subsídios dados, com vistas, principalmente, à implementação de programas de conservação e substituição de energéticos importados.

Um sistema de subsídios, desde que bem planejado e criteriosamente definido, será vantajoso para o paĺs, pois se estará economizando divisas - problema financeiro básico - permitindo diminuir o grau de dependência externa, induzindo a uma mudança no sistema produtivo vigente, para um outro que melhor se amolde à realidade de um pais em desenvolvimento (carente de recursos fi. nanceiros), buscando encontrar padrões de consumo (bem-estar) condizentes com as necessidades básicas de crescimento do seu mercado interno.

\section{Metodologia de previsão do mercado de energia elétrica}

\section{PAULO DE VILHENA BRANDÃO}

Chefe do Departamento de Mercado da Diretoria de Planejamento e Engenharia da ELE. TROBRÁS.

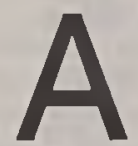
presenta-se, aqui, uma descrição sumária da metodologia atualmente adotada no tocante à previsão do mercado de energia elétrica no Brasil, com ênfa. se nos aspectos de longo prazo. No item 2. apontam-se algumas características gerais dos estudos de mercado, realiza. dos correntemente no Setor Elétrico. A seguir, são descritas, de forma sucinta, as abordagens metodológicas utilizadas para a previsão do consumo, por categoria (item 3) e dos requisitos de ener. gia e ponta (item 4).

\section{Caracteristicas gerais da metodologia utilizada}

A previsão do mercado de energia elé trica no Brasil, resulta de um processo iterativo, no qual a ELETROBRAS, que atua como coordenadora dos estudos, responsabiliza-se pela preparação de previsōes, a nivel nacional e regional, que servem como elementos balizadores na análise das previsões de mercado das 61 concessionárias, cujo controle acionário pode estar no nível federal, estadual municipal ou mesmo privado. Este fracionamento dos estudos de mercado decorre, sobretudo, das dimensōes continentais do país, que determina estrutu. ras sócio-econômicas e disponibilidades de recursos energéticos bastante diferenciadas entre regiōes e que, necessariamente, se refletem na configuração dos mercados de energia.

Os requisitos do mercado de energia elétrica são estimados com base em hi. póteses sobre a evolução provável de um conjunto de variáveis macro-económicas, demográficas e habitacionais e com base em informaçőes quanto a programas setoriais especificos, a nivel federal e estadual e quanto a novos contratos de suprimento de porte significativo. Leva-se em conta o comportamento pretérito do mercado, considerando, porém, além da tendência, eventuais distorções das series históricas, devidas à inadequação do atendimento no passado.

Complementando estas análises, realizam-se freqüentemente estudos especificos sobre os principais setores do mercado industrial, e sobre as possibilidades de racionalização do emprego dos recursos energéticos disponíveis, mediante adoção de mecanismos para promover a conservação e substituição, como, por exemplo, de derivados de petróleo por eletricidade.

O horizonte e o detalhamento das previsões, por tipo e localização do consumo, variam com a finalidade a que se destinam, tal como o planejamento dos sistemas geradores, de transmissão e de distribuição, para os quais são distintos o escopo e o prazo de maturação das decisões. Tendo em vista ainda que, para os primeiros anos da previsão, o volume e a confiabilidade das informações disponíveis são bem maiores do que para os demais, desdobra-se a análise da evolução do mercado em dois períodos básicos, aos quais aplicam-se critérios ligeiramente diferentes.

Para os primeiros três anos de estudos, o consumo por categoria, os indices de perdas, o fator de carga e vendas em grosso, são previstos, segundo metodologia especiffica, constante da Portaria 760 do DNAEE. Para o longo prazo (com horizonte de 20 a 30 anos), a principal referência adotada é o crescimen. to dos grandes agregados macroeconômicos e demográficos. A vinculação do consumo com os mesmos, particular. mente a elasticidade-renda, é o principal objeto de análise, uma vez que, dada à margem possível de variação destes, o consumo previsto pode sofrer alteraçōes substanciais. A variação da relação en tre os crescimentos do consumo e da renda reflete, essencialmente, alterações na na. tureza do mercado. Essa elasticidade será, tanto maior, quanto mais predomina. rem, entre os novos consumidores, aqueles de elevado consumo de energia elétrica por unidade de produto.

As previsões de longo prazo são elaboradas segundo metodologia que se caracteriza por: 